\title{
Obesity and the pubertal transition in girls and boys
}

\author{
Christine M Burt Solorzano ${ }^{1,2}$ and Christopher R McCartney ${ }^{2,3}$ \\ ${ }^{1}$ Division of Endocrinology, Department of Pediatrics, ${ }^{2}$ Center for Research in Reproduction and ${ }^{3}$ Division of \\ Endocrinology and Metabolism, Department of Medicine, University of Virginia Health System, PO Box 800391, \\ Charlottesville, Virginia 22908, USA \\ Correspondence should be addressed to C R McCartney at Division of Endocrinology and Metabolism, Department of Medicine, \\ Center for Research in Reproduction, University of Virginia Health System; Email: cm2hq@virginia.edu
}

\begin{abstract}
Childhood obesity has become a major health concern in recent decades, especially with regard to metabolic abnormalities that impart a high risk for future cardiovascular disease. Recent data suggest that excess adiposity during childhood may influence pubertal development as well. In particular, excess adiposity during childhood may advance puberty in girls and delay puberty in boys. Obesity in peripubertal girls may also be associated with hyperandrogenemia and a high risk of adolescent polycystic ovary syndrome. How obesity may perturb various hormonal aspects of pubertal development remains unclear, but potential mechanisms are discussed herein. Insulin resistance and compensatory hyperinsulinemia may represent a common thread contributing to many of the pubertal changes reported to occur with childhood obesity. Our understanding of obesity's impact on pubertal development is in its infancy, and more research into pathophysiological mechanisms and longer-term sequelae is important.
\end{abstract}

Reproduction (2010) 140 399-410

\section{Introduction}

Puberty is the complex process by which children develop secondary sexual characteristics and reproductive competence. Normal puberty is initiated centrally, with gonadal function being driven by increased GNRH and gonadotropin secretion. Among other factors, adequate nutritional status appears to be requisite for the central initiation of puberty.

Childhood obesity - a result of relative overnutrition has become a major health concern in recent decades. A marked increase in the prevalence of childhood and adolescent obesity is well documented. For example, while an estimated $4.2 \%$ of $6-11$ year olds and $4.6 \%$ of 12-19 year olds in the US were obese in the 1960s (Ogden et al. 2002), these estimates had increased to 19.6 and $18.1 \%$ respectively by the $2007-2008$ time period (Ogden et al. 2010). An increase in childhood obesity prevalence has been observed worldwide, in both developed and developing countries (Wang \& Lobstein 2006).

Childhood obesity and adolescent obesity are associated with a number of medical complications, among the most worrisome being metabolic risk factors for

This paper is one of five papers that form part of a special Focus Issue section on Obesity. The Guest Editor for this section was J E Norman, Edinburgh, UK. future atherosclerotic vascular disease (e.g. insulin resistance, hyperglycemia, hypertension, and dyslipidemia; Cali \& Caprio 2008). Excess adiposity may also influence various aspects of pubertal development, such as the timing of pubertal initiation and hormonal parameters during puberty. These alterations may not be innocuous. For example, earlier puberty in girls appears to be associated with a higher risk of psychological problems, risk-taking behavior, and even future breast cancer (Golub et al. 2008). Obesity during the pubertal transition may also promote the development of adolescent polycystic ovary syndrome (PCOS; Franks 2008).

In this review, we describe some of the potential mechanisms by which obesity may perturb various aspects of pubertal development.

\section{The physiology of normal puberty}

\section{Reactivation of the hypothalamic-pituitary-gonadal axis}

During mid-late fetal life and infancy, both girls and boys exhibit significant hypothalamic GNRH secretory activity, which in turn stimulates pituitary gonadotropin secretion and gonadal hormone production (the 'minipuberty' of infancy; Grumbach 2002). The GNRH pulse generator then enters a state of quiescence, and gonadotropin and sex steroid secretion fall to very low 
levels (the 'juvenile pause'). Mechanisms responsible for the childhood suppression and pubertal resurgence of $\mathrm{GNRH}$ pulse generator activity remain poorly understood. Although a detailed description of known pathways is beyond the scope of this review, available data point to the importance of inhibitory pathways involving $\gamma$-aminobutyric acid during childhood, stimulatory pathways involving glutamate and kisspeptin at puberty, interactions between glia and GNRH neurons, etc. (Ojeda et al. 2006). These data, which were largely derived from animal studies, are the subject of several excellent reviews (Terasawa \& Fernandez 2001, Ojeda et al. 2006, Plant 2008). In essence, the increase in pulsatile GNRH secretion at puberty represents the cumulative effect of highly complex and intricate hypothalamic interactions that are markedly influenced by genetic factors and environmental signals.

Patterns of gonadotropin secretion across normal puberty are well described (Grumbach 2002). LH (and by inference GNRH) pulsatility again becomes evident by mid-childhood, with low frequency and amplitude LH pulses initially being detected during sleep only. However, such low-level gonadotropin secretion is inadequate to drive substantial gonadal sex steroid production. The beginning of puberty is characterized by marked increases in GNRH and gonadotropin secretion. During early puberty, this amplification of pulsatile gonadotropin secretion is sleep entrained, with relative quiescence during the day. This is accompanied by early morning peaks of sex steroid concentrations (e.g. estradiol $\left(\mathrm{E}_{2}\right)$ and testosterone). As puberty progresses, pulsatile gonadotropin secretion gradually increases during the daytime, and an adult pattern of gonadotropin secretion is eventually established. By the end of puberty in boys, day-to-day GNRH and gonadotropin secretion remains fairly constant. In contrast, secretion of GNRH and gonadotropins in mature girls is dynamic and related to menstrual cycling.

\section{Development of secondary sexual characteristics}

In girls, maturation of gonadotropin secretion promotes ovarian follicular development, $E_{2}$ production, and eventual ovulation. In boys, increasing gonadotropin release leads to testicular enlargement and testosterone secretion. Increased sex steroid production continues across puberty, promoting the clinical signs of pubertal development (e.g. secondary sex characteristics). These morphological changes of puberty typically begin between the ages of 8 and 12 years in girls, and between 9 and 14 years in boys, although the timing of pubertal initiation is influenced by a number of factors, including genetic factors (e.g. race and ethnicity; Euling et al. 2008).

Thelarche, the initial appearance of breast tissue in girls (beginning as a 'breast bud' underneath the areola), normally indicates gonadotropin-driven ovarian estrogen production. Increasing estrogen secretion in girls promotes continued breast development; it also contributes to the pubertal changes of body fat composition and distribution. Menarche, the onset of menstruation, denotes increasing maturity of the GNRH pulse generator and follicular development, but does not necessarily imply ovulatory cycles. Regular, ovulatory cycles typically develop within 2 years of menarche.

Gonadarche, a term designating testicular enlargement in boys from a prepubertal volume of $1-2 \mathrm{ml}$ to a pubertal volume exceeding $3 \mathrm{ml}$, coincides with increased testicular androgen production. Gonadarche is followed by progressive masculinization, which includes increasing penile length and width, scrotal development (thinning, rugation, and pigmentation), male-pattern hair development, and changes of the musculoskeletal system.

The above physical changes of puberty (e.g. development of female breast tissue and maturation of male genitalia) are most commonly documented using clinical stages (from 1 (prepubertal) to 5 (fully mature)) delineated by Marshall \& Tanner $(1969,1970)$ approximately four decades ago. Although initial descriptions of Tanner staging were by visual inspection alone, the most accurate way of determining thelarche and gonadarche is by palpation. This is especially relevant in girls with obesity, as it is difficult to distinguish glandular breast tissue from adipomastia by inspection alone.

\section{Adrenarche and pubarche}

Adrenarche is a term describing increased adrenocortical androgen production in both boys and girls (Auchus \& Rainey 2004). Adrenarche usually begins at a mean age of 6-7 years, significantly earlier than physical signs of puberty appear. This process is characterized by increasing thickness of the adrenal zona reticularis, changes of adrenal enzyme activities, and rising levels of $\Delta^{5}$ and $\Delta^{4}$ steroids including DHEA, its sulfated product DHEA-S, and androstenedione. Clinically, adrenarche is followed by the appearance of pubic hair (pubarche), axillary hair, acne, and adult apocrine odor. The factors responsible for adrenal maturation remain unclear, but are partly dependent on pituitary secretion of ACTH. Although pubarche is often closely associated with the timing of pubertal onset (e.g. thelarche in girls and gonadarche in boys), it can be temporally unrelated to gonadotropin production. Therefore, pubarche does not represent evidence of gonadotropin-dependent puberty. However, the role of adrenal androgen production in the central initiation of normal puberty in humans remains unknown.

\section{Linear growth}

$\mathrm{GH}$ and insulin-like growth factor 1 (IGF1) levels also increase markedly during puberty. Along with sex steroids (especially $E_{2}$ ), these hormones are responsible 
for the pubertal growth spurt. Indeed, sex steroids have a marked influence on linear growth and the GH-IGF1 axis (Mauras 2001). For example, GH secretion, IGF1 levels, and IGF1 response to exogenous GH correlate positively with endogenous sex steroid production during puberty in both sexes (Mansfield et al. 1988, Coutant et al. 2004). Moreover, testosterone administration in pre- and peripubertal boys increases spontaneous and stimulated $\mathrm{GH}$ secretion with concomitant increases in baseline and GH-stimulated IGF1 levels (Mauras 2001). Interestingly, aromatization of androgens to estrogens appears to be required for this effect in boys: administration of dihydrotestosterone, a potent but non-aromatizable androgen, does not increase $\mathrm{GH}$ secretion, and estrogen receptor antagonism prevents $\mathrm{GH}$ stimulation by androgens (Mauras 2001). In girls, $\mathrm{GH}$ production increases with exogenous estrogen therapy (Mauras 2001, Coutant et al. 2004). However, GH-stimulated IGF1 production decreases with exogenous estrogen administration in late-pubertal girls, unlike the response to testosterone seen in late-pubertal boys (Coutant et al. 2004).

\section{Timing and tempo of pubertal development in obese children}

A multitude of factors appear to affect the timing and tempo of pubertal development, including environmental influences. Chronic malnutrition delays the onset of puberty and slows its progression (Dunger et al. 2005, Euling et al. 2008). In industrialized nations, the age of menarche has markedly decreased since the 19th century, likely related to substantial improvements in nutrition, sanitation, and general health (Kaplowitz 2008). While adequate nutrition is a key permissive factor for normal timing and tempo of pubertal development, it remains unclear whether these things are altered by relative overnutrition leading to excessive adiposity.

\section{Secular trends of pubertal timing and adiposity}

Much interest has focused on putative secular trends (i.e. changing distribution of a population parameter over time) of pubertal timing since the mid-1900s. This topic has been controversial, in large part related to important study differences that can limit the validity of comparisons across time (Euling et al. 2008). Despite the limitations of available data, a majority of members of an expert panel recently concluded that data collected from 1940 to 1994 support the contention that thelarche and menarche are occurring earlier in US girls (Euling et al. 2008). This panel felt that data were insufficient to establish recent secular trends of pubertal onset in US boys.
Of interest, these apparent trends have coincided with the increase in obesity prevalence, leading to speculation that increasing adiposity and earlier pubertal development in girls are directly related. This hypothesis remains controversial, and data supporting this contention have recently been reviewed (Biro et al. 2006, Slyper 2006, Jasik \& Lustig 2008, Kaplowitz 2008). As examples, studies have suggested that girls with early breast development have greater adiposity (body mass index (BMI) and skinfold thickness) compared with agematched girls without thelarche (Herman-Giddens et al. 1997, Kaplowitz et al. 2001, Wang 2002), that girls with excessive BMI are more likely to have thelarche between ages 8.0 and 9.6 years compared with girls with normal BMI (Rosenfield et al. 2009), and that age at menarche is negatively associated with BMI (Freedman et al. 2002).

While these data are intriguing, it is important to recognize that to some degree, weight gain during puberty is physiologic: normal puberty in girls is accompanied by increases in BMI and subcutaneous adiposity. Thus, early puberty from any cause can produce physiological increases in parameters frequently used to define obesity, including age-normalized BMI. However, adiposity in early childhood also appears to be linked to advanced puberty in girls. For example, in a prospective study of girls in the US, earlier thelarche was positively associated with elevated agenormalized BMIs at age 3 years and with increased velocity of BMI change from age 3 years to first grade (average age of 7 years; Lee et al. 2007). These and other data (Davison et al. 2003) suggest that increased adiposity precedes early puberty in many of these girls. Nonetheless, the above data do not prove a direct, causal relationship between excessive adiposity and early puberty. These phenomena may be coincidental. It is also possible that abnormalities affecting the hypothalamic-pituitary unit can promote both early puberty and early, abnormal weight gain (Ong et al. 2006). Some intriguing hypotheses hold that early conditions and/or exposures (e.g. low birth weight with rapid catch-up growth and dietary factors during infancy) may predispose children to earlier pubertal maturation in addition to increasing the risk of future insulin resistance and obesity (Ahmed et al. 2009, DiVall \& Radovick 2009). How these early factors could 'program' future risk has not been established.

\section{The putative influence of obesity on pubertal maturation: additional considerations}

Potential mechanisms underlying the putative association between childhood obesity and earlier pubertal onset in girls remain unclear (Fig. 1). This uncertainty is partly related to the enigmatic nature of normal pubertal initiation and progression. Adiposity has been proposed as a metabolic gatekeeper of central pubertal initiation, 
A



B

Increased fat tissue compartment

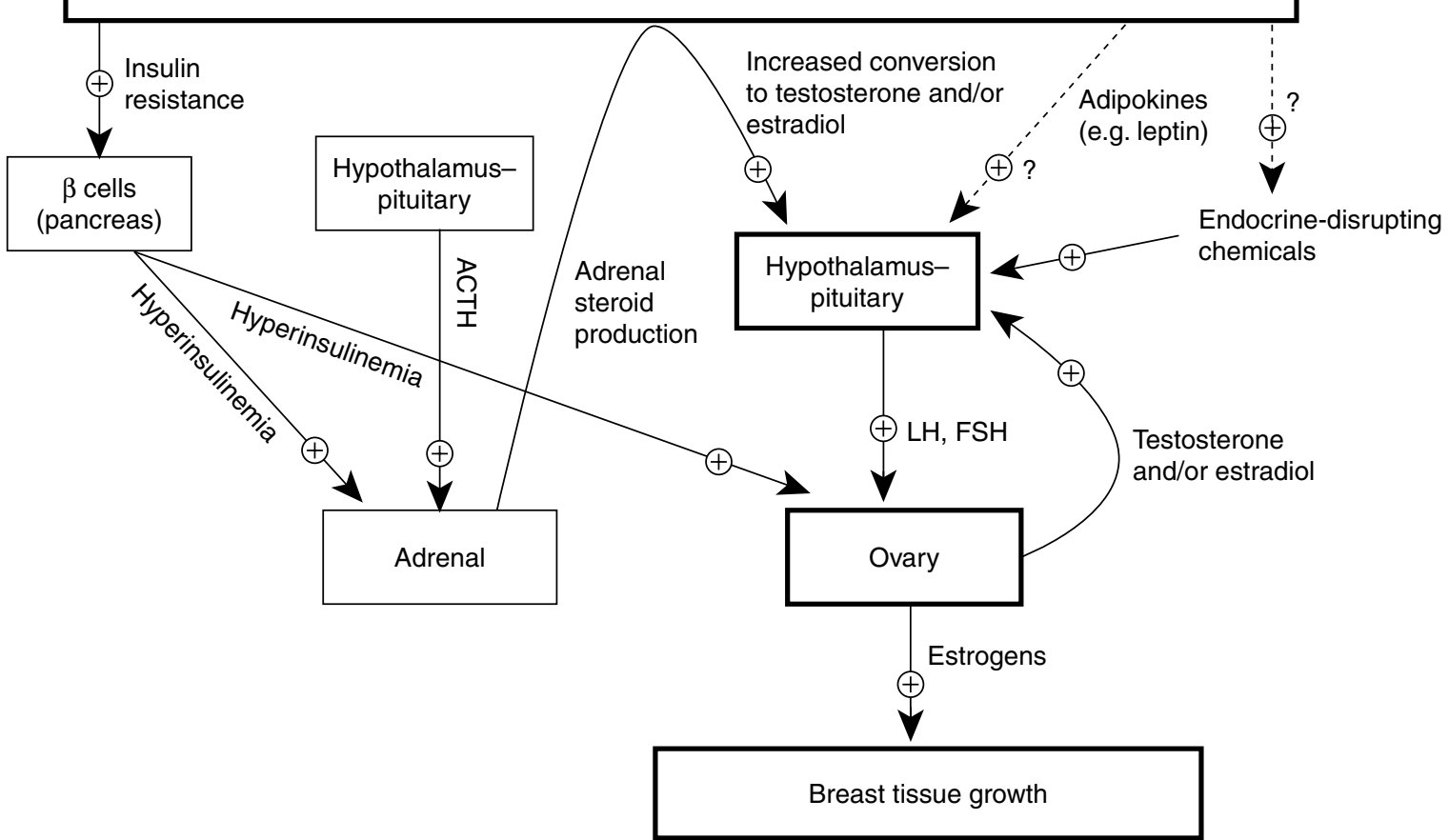

Figure 1 Simplified schematic diagram of potential mechanisms by which increased adiposity could lead to early thelarche in girls. For the sake of clarity, separate diagrams highlight gonadotropin-independent (A) and gonadotropin-dependent (B) mechanisms. However, gonadotropinindependent and gonadotropin-dependent mechanisms may be involved concurrently. 
so obesity may possibly be associated with premature activation of the GNRH pulse generator and central initiation of puberty.

As described above, the prototypical morphological changes of puberty (e.g. thelarche) usually imply preceding the activation of the GNRH-gonadotropin axis. However, it remains unknown whether or not early thelarche in obese girls reflects neuroendocrine maturation. Indeed, estrogens from any source can promote breast tissue development, so it remains possible that early signs of puberty (thelarche) do not generally reflect normal maturation of the hypothalamic-pituitaryovarian axis in obese girls (Ahmed et al. 2009). Of interest in this regard, adipose tissue is replete with aromatase, which can produce estrogens from adrenal androgen precursors (e.g. androstenedione; Dunger et al. 2005, Jasik \& Lustig 2008). Other potential mechanisms contributing to increased estrogens in obesity include an obesity-associated decrease in the hepatic metabolism of estrogens (Jasik \& Lustig 2008). Additionally, peripubertal obesity is associated with insulin-induced reductions in sex hormone-binding globulin (SHBG; Reinehr et al. 2005, McCartney et al. 2007, Ahmed et al. 2009), which increases bioavailability of sex steroids including $E_{2}$.

It is unknown whether prolonged exposure to excess estrogen for age - at least to the degree putatively observed in prepubertal girls with obesity - could contribute to secondary central precocious puberty. Most girls with McCune-Albright syndrome and autonomous ovarian estrogen secretion eventually develop early pubertal hypothalamic-pituitary activation requiring GNRH agonist therapy (Lee \& Houk 2007). On the other hand, while exogenous estrogen exposure may lead to gonadotropin-independent precocious thelarche, no case of secondary central precocious puberty has been reported after such exposure (Partsch \& Sippell 2001).

We know of no data in girls clearly suggesting that obesity is associated with premature activation of gonadotropin secretion. In fact, two recent studies in early pubertal girls suggest that excessive weight is associated with a blunted sleep-related rise in LH (Bordini et al. 2009, McCartney et al. 2009). Additionally, while obesity in girls may be associated with earlier evidence of pubertal development (thelarche), some studies suggest that the tempo of pubertal development (e.g. time from thelarche to menarche) is slowed in the setting of obesity (Jasik \& Lustig 2008). Such a phenomenon would be consistent with obesity-related estrogenization without true advancement of central (gonadotropin-dependent) puberty. Furthermore, isolated menses do not necessarily imply early maturation of the hypothalamicpituitary unit, as perimenarcheal menses can represent non-ovulatory bleeding.

\section{The putative influence of obesity on pubertal maturation: potential mechanisms}

\section{Potential role of hormones regulating energy homeostasis}

Several decades ago, Frish et al. proposed that attainment of a certain minimum weight or body fat percentage was requisite for pubertal development and menstrual function (the 'critical weight hypothesis'; Jasik \& Lustig 2008, Kaplowitz 2008, Ahmed et al. 2009). The characterization of leptin - a hormone produced by adipocytes (i.e. an adipokine) - provided some support for this notion. Leptin concentrations are directly correlated with fat mass, and leptin serves as a signal to the hypothalamus regarding energy stores in the adipose tissue compartment. Physiological effects of leptin include appetite reduction and increased thermogenesis, but leptin appears to play a role in pubertal development as well (Shalitin \& Phillip 2003, Jasik \& Lustig 2008, Kaplowitz 2008, Martos-Moreno et al. 2010). For example, patients with leptin mutations have hypogonadotropic hypogonadism and failure to enter puberty; these can be reversed with leptin therapy. A similar phenotype occurs in those with leptin receptor mutations. Presumably, an adequate concentration of leptin communicates to the CNS that energy stores are adequate for the energy-intensive process of pubertal development; this permits central activation of GNRH and gonadotropin secretion. Leptin may also have more direct stimulatory effects on GNRH and gonadotropin secretion (Kaplowitz 2008). For example, in rodent models, leptin receptors are found on kisspeptin-producing hypothalamic neurons and pituitary gonadotropes, leptin can accelerate GNRH pulse frequency, and leptin can directly stimulate LH and FSH release (Kaplowitz 2008, Martos-Moreno et al. 2010). Leptin may also influence gonadal function as well (Martos-Moreno et al. 2010). Although leptin is clearly important as a permissive factor, leptin alone does not appear to be sufficient to initiate puberty. For instance, increases in leptin concentrations do not closely correspond to pubertal initiation, leptin administration does not consistently advance puberty in animal models, and leptin is not sufficient to produce precocious puberty (Kaplowitz 2008, Ahmed et al. 2009).

Other factors relevant to obesity may contribute to the metabolic regulation of reproductive function, although their potential roles in pubertal maturation remain uncertain. For example, the orexigenic hormone ghrelin can influence the hypothalamicpituitary-gonadal axis, and has been hypothesized to influence pubertal events (Tena-Sempere 2008, Martos-Moreno et al. 2010). In addition, insulin has been proposed as a contributor to pubertal maturation (Jasik \& Lustig 2008). 


\section{Potential role of obesity-related insulin resistance with compensatory hyperinsulinemia}

Reductions in insulin sensitivity and compensatory hyperinsulinemia are physiological during puberty, and this partly reflects the effects of increased GH and IGF1 (Moran et al. 2002). Increased insulin secretion may facilitate pubertal weight gain and growth, perhaps in part by contributing to leptin resistance (Lee 2006, Jasik \& Lustig 2008). Physiological insulin resistance may also be involved in the initiation of adrenarche (Saenger \& Dimartino-Nardi 2001). Furthermore, hyperinsulinemia can reduce hepatic SHBG production, increasing sex steroid bioavailability, and in adult women, insulin can augment LH-stimulated ovarian steroidogenesis (Poretsky et al. 1999).

Notably, the insulin resistance of puberty may be exaggerated in the setting of obesity, especially in girls (Roemmich et al. 2002, Brufani et al. 2009, Pilia et al. 2009). Thus, exaggerated pubertal insulin resistance and hyperinsulinemia may partly account for advancement of pubertal maturation in children with obesity. Also of interest, greater degrees of insulin resistance in AfricanAmerican children might help explain why such children generally attain pubertal milestones earlier than their Caucasian counterparts (Sun et al. 2002, Casazza et al. 2008, Hoffman 2009).

Premature and/or exaggerated adrenarche may be a consequence of obesity in some individuals (Saenger \& Dimartino-Nardi 2001, Dunger et al. 2005); this may provide ample substrate for aromatization in fat tissue, contributing to early estrogenization in girls. Possible mechanisms accounting for increased adrenal androgen production in obesity include hyperinsulinemia and hyperleptinemia, both of which may stimulate abnormal adrenal steroidogenesis (Shalitin \& Phillip 2003, Kaplowitz 2008). Ibanez et al. (2000, 2006a) have reported that the constellation of low birth weight, early postnatal catch-up growth, and precocious pubarche is associated with early puberty. In these girls, metformin administration delayed thelarche and menarche (Ibanez et al. 2006b, 2006c), suggesting that hyperinsulinemia may play a role in early pubertal development in this population of girls. Another potential mechanism of increased adrenal steroidogenesis relates to increased $11 \beta$-hydroxysteroid dehydrogenase activity in an expanded fatty tissue compartment, which can lead to enhanced deactivation of cortisol and subsequent increases in ACTH drive, thereby increasing adrenal androgen production (Dunger et al. 2005).

\section{Potential role of androgens in girls}

As described below, peripubertal obesity appears to be associated with hyperandrogenemia in peripubertal girls. Blank et al. (2009) have hypothesized that androgens play a key role in the central initiation of puberty, with increasing androgens (perhaps adrenal in origin during normal puberty) serving to decrease GNRH pulse generator sensitivity to negative feedback suppression by sex steroids (e.g. progesterone). If this concept is correct, then high androgen concentrations related to obesity in prepubertal girls could facilitate the pubertal increase in pulsatile GNRH secretion, possibly leading to earlier pubertal onset. As mentioned above, two studies suggest that $\mathrm{LH}$ secretion is blunted in pre- and early pubertal girls with obesity. However, not all obese girls have hyperandrogenemia (McCartney et al. 2007, Knudsen et al. 2010), and early pubertal girls in both of the aforementioned studies had normal androgen concentrations (Bordini et al. 2009, McCartney et al. 2009).

Thus, it remains possible that young girls with hyperandrogenemia experience early puberty related to androgen stimulation of GNRH secretion. In support of this idea, children with poorly controlled congenital adrenal hyperplasia first experience early development of secondary sexual characteristics - from conversion of adrenal androgens to testosterone or aromatization to estrogens - and then central initiation of precocious puberty (Dunger et al. 2005).

Also of interest, recent rodent studies disclosed earlier puberty (indicated by timing of vaginal opening) in rodents fed high-fat diets (Boukouvalas et al. 2008, Brill \& Moenter 2009). In one of these studies, early vaginal opening in mice on high-fat diet was reversed with androgen receptor blockade (flutamide; Brill \& Moenter 2009). Flutamide also delayed vaginal opening in control mice, indicating that androgens may influence the timing of puberty (vaginal opening) in both overfed and normal mice. Interestingly, metformin given to mice on high-fat diet normalized vaginal opening, but had no effect on control mice (Brill \& Moenter 2009). This suggests that hyperinsulinemia in mice plays a role in diet-induced advancement of vaginal opening (presumably by promoting hyperandrogenemia), but not in normal pubertal initiation. Importantly, vaginal opening in rodents reflects exposure to pubertal sex steroid levels, but does not necessarily imply central activation of gonadotropin secretion.

\section{Potential role of endocrine disruptors}

Low-level exposure to endocrine disruptors - environmental chemicals that interfere with normal endocrine physiology through a variety of mechanisms - may also contribute to altered pubertal development (Dunger et al. 2005, Biro et al. 2006, Kaplowitz 2006). These data have recently been reviewed (Den Hond \& Schoeters 2006, McLachlan et al. 2006). For example, pesticides and exogenous hormones in hair care and cosmetic products have been implicated as possible causes of premature puberty. Indeed, exposure to environmental chemicals with estrogenic properties can produce early thelarche in girls - a likely example of secondary sexual 
characteristics without central puberty. Environmental chemicals may also influence puberty by virtue of their anti-estrogen or anti-androgen effects. Moreover, exposure to endocrine disruptors at various stages of development (including gestational) could influence the central initiation of puberty (Den Hond \& Schoeters 2006, McLachlan et al. 2006).

The effects of endocrine disruptors can be complex, potentially involving epigenetic changes. Additionally, the putative influence of endocrine disruptors on pubertal development, which may be subtle on the population level, is difficult to study in humans. Consequently, the degree to which low-level exposure to endocrine disruptors influences pubertal development in the general population - and whether this putative effect is influenced by obesity - remains unknown. It is possible that some endocrine disruptors contribute to both early puberty and obesity, or that endocrine disruptors influencing puberty may disproportionately affect obese children. This is an important area for future research.

\section{Pubertal timing in boys with obesity}

Fewer data are available in boys, in part because pubertal development in boys is more difficult to ascertain on a large scale. Although available data are mixed (Jasik \& Lustig 2008, Kaplowitz 2008, Ahmed et al. 2009), pubertal development in obese boys may be delayed rather than advanced (Kaplowitz 1998, Wang 2002, Lee et al. 2010). Reasons for this putative phenomenon are unclear. However, obesity in men can be associated with a form of hypogonadotropic hypogonadism - perhaps related to increased aromatization of androgens to estrogens and subsequent feedback inhibition of gonadotropin secretion (Hammoud et al. 2006). It is possible that similar mechanisms are operative in obese boys, but few specific data regarding gonadotropins and sex steroids are available in this group. Researchers in China recently found significantly greater testicular volume (assessed by ultrasound) in obese prepubertal boys compared with age-matched prepubertal controls (mean values $\sim 1.18$ vs $0.82 \mathrm{ml}$; Fu et al. 2006). Median morning (0700-0900 h) inhibin B, DHEA, and DHEA-S concentrations - in addition to bone age - were also higher in the obese group. However, morning FSH concentrations were similarly low (median values $1.5 \mathrm{IU} / \mathrm{l}$ in obese versus $1.65 \mathrm{IU} / \mathrm{l}$ in controls), and morning $\mathrm{LH}$ and testosterone were undetectable in most subjects, with no differences between groups. Although increased testicular size in these obese boys could be consistent with early activation of overnight gonadotropin secretion, the latter was not measured.

\section{Obesity and hyperandrogenemia in peripubertal girls}

Peripubertal obesity in girls has been associated with hyperandrogenemia in some (Reinehr et al. 2005, McCartney et al. 2006, 2007), although not all (Bordini et al. 2009), studies. For example, investigators in Germany found that compared with their normal weight counterparts, obese pre- and pubertal girls had total testosterone levels that were 4- and 1.75-fold elevated respectively, while SHBG was 26 and $44 \%$ lower respectively (Reinehr et al. 2005). These abnormalities improved with weight loss (Reinehr et al. 2005). A study of girls in the US by our group suggested that free testosterone was 5.0-fold higher in obese pre- to midpubertal girls (Tanner stages 1-3; McCartney et al. 2006). A later study by our group demonstrated significant hyperandrogenemia during each stage of puberty, with differences being especially marked in pre- and early pubertal girls (Fig. 2; McCartney et al. 2007). The findings of increased total testosterone and reduced SHBG in these studies imply both increased testosterone production and bioavailability in obese girls.

\section{Relationship between hyperandrogenemia and insulin in peripubertal girls with obesity}

The etiology of hyperandrogenemia in some obese girls is unclear, but insulin resistance with compensatory hyperinsulinemia likely plays a key role.
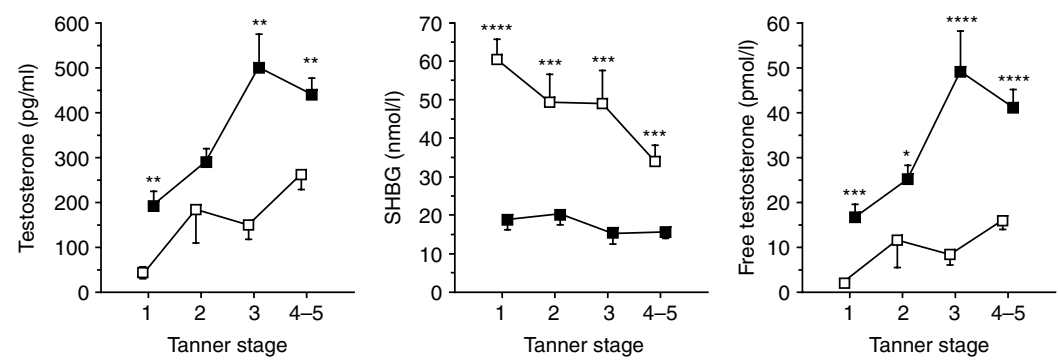

Figure 2 Total testosterone, SHBG, and free testosterone concentrations in obese (BMI-for-age percentile $\geq 95$; solid squares) and normal-weight girls (BMI-for-age percentile < 85; open squares) grouped by Tanner stage. Data are shown as mean \pm s.E.M. Differences were assessed with Wilcoxon rank sum tests: ${ }^{*} P<0.05 ;{ }^{* *} P \leq 0.01 ;{ }^{* *} P \leq 0.001 ;{ }^{* * * *} P \leq 0.0001$ before Bonferroni correction. Conversion from conventional to $\mathrm{SI}$ units: total testosterone $\times 3.47$ (nmol/l). Data used, with permission, from McCartney CR, Blank SK, Prendergast KA, Chhabra S, Eagleson CA, Helm KD, Yoo R, Chang RJ, Foster CM, Caprio S et al. 2007 Obesity and sex steroid changes across puberty: evidence for marked hyperandrogenemia in pre- and early pubertal obese girls. Journal of Clinical Endocrinology and Metabolism 92 430-436. (c) 2007 The Endocrine Society. 
The pathophysiological connection between hyperinsulinemia and hyperandrogenemia was initially suggested by the observation that syndromes of extreme insulin resistance can be associated with marked ovarian hyperandrogenemia. Subsequent studies of PCOS have provided compelling evidence of hyperinsulinemia's ability to promote androgen production in women. For example, in in vitro studies, insulin has potent tropic actions on ovarian theca-stromal cells, insulin augments $\mathrm{LH}$-induced androgen production, and high doses of insulin can stimulate theca cell androgen production even in the absence of LH (Poretsky et al. 1999). Hyperandrogenemia in PCOS is ameliorated with varied maneuvers that reduce hyperinsulinemia, such as weight loss and pharmacological treatment with diazoxide, octreotide, D-chiro-inositol, metformin, and thiazolinediones (Poretsky et al. 1999, Baillargeon et al. 2003). Moreover, hyperinsulinemia decreases hepatic production of SHBG - resulting in increased androgen bioavailability (i.e. increased free testosterone) - which may also be reversed with insulin lowering therapies (Poretsky et al. 1999, Baillargeon et al. 2003). Hyperinsulinemia may also promote excessive androgen production by the adrenal glands (Auchus \& Rainey 2004), and it may increase IGF1 bioavailability via reductions in IGF-binding proteins (IGFBPs), with IGF1 contributing to adrenal and ovarian androgen production (Tfayli \& Arslanian 2008).

As a group, obese peripubertal girls demonstrate insulin resistance and hyperinsulinemia (Cali \& Caprio 2008). Our earlier studies in pubertal girls demonstrated a positive correlation between fasting insulin and free testosterone (McCartney et al. 2006, 2007). Moreover, a recent analysis suggests that fasting insulin predicts free testosterone concentrations in obese peripubertal girls independent of $\mathrm{BMI} z$-score, age, pubertal stage, $\mathrm{LH}$, and IGF1 (Knudsen et al. 2010). These data are also in keeping with a recent study in rats, in which experimental hyperinsulinemia (i.e. insulin infusion to raise insulin levels by $\sim 66 \%$ ) was started at age 28 days and continued for 4 weeks (encompassing the time of puberty, since vaginal opening occurred by 40 days of age; Chakrabarty et al. 2006). These insulin-treated rats demonstrated serum testosterone and DHEA-S elevations, proliferation of the ovarian theca and interfollicular stroma compartments, and irregular estrous cycles.

\section{Obesity-associated hyperandrogenemia: potential role of abnormal $\mathrm{LH}$ secretion}

Abnormal LH secretion may also contribute to obesityassociated hyperandrogenemia. LH is the proximal stimulus for theca cell androgen production, and $\mathrm{LH}$ is a key permissive factor in the ovarian hyperandrogenemia of PCOS. In general, LH concentrations appear to be decreased in obese early to mid-pubertal girls compared with normal weight girls of similar pubertal stage (McCartney et al. 2007, 2009); this appears to be analogous to what is observed in obese versus non-obese PCOS. Nonetheless, a partial correlation analysis of obese and non-obese peripubertal girls suggested that $\mathrm{LH}$ is an independent predictor of free testosterone, even after adjusting for differences in age, pubertal stage, BMI, fasting insulin, and DHEA-S (McCartney et al. 2006). Similarly, a recent analysis of 92 obese peripubertal girls suggested that morning LH concentrations independently predict free testosterone better than fasting insulin, BMI $z$-score, age, pubertal stage, and IGF1 (Knudsen et al. 2010).

The aforementioned relationship between $\mathrm{LH}$ and free testosterone in obese peripubertal girls could also reflect an effect of androgens to promote GNRH secretion. Excess LH secretion in PCOS is partly related to relative GNRH pulse generator resistance to the negative feedback actions of progesterone (Burt Solorzano et al. 2010). This defect is reversed in adult PCOS by androgen receptor blockade (Eagleson et al. 2000), suggesting that hyperandrogenemia per se contributes to abnormal neuroendocrine function in PCOS. Data in animal models support the idea that androgens increase GNRH pulsatility - either directly or by interfering with feedback suppression (Robinson et al. 1999, Pielecka et al. 2006). Limited data in adolescent hyperandrogenemia suggest that hyperinsulinemia may also contribute to this effect (Blank et al. 2009).

\section{Potential relevance of peripubertal hyperandrogenemia to the genesis of adolescent PCOS}

Hyperandrogenemia often has no clinical manifestations prior to or during early puberty, but in many adolescents with PCOS, initial signs developed during or soon after puberty (Shayya \& Chang 2010). Despite its subclinical presentation in many pre- and early pubertal girls, hyperandrogenemia during early adolescence may represent a precursor of adult PCOS (Franks 2002, Witchel 2006). Thus, the association between peripubertal obesity and hyperandrogenemia may suggest that obese girls are at high risk for future PCOS (Rosenfield 2007). Indeed, the prevalence of adolescent PCOS has ostensibly increased in parallel with that of adolescent obesity (Franks 2008), although we are unaware of formal prevalence studies demonstrating such. Therefore, the relationships among peripubertal obesity, hyperinsulinemia, hyperandrogenemia, and risk of future PCOS are important areas for future study.

Our group has hypothesized that obesity-related hyperinsulinemia can produce hyperandrogenemia during the pubertal transition, and in susceptible individuals, this hyperandrogenemia may interfere with normal negative feedback mechanisms at the GNRH pulse generator, enhancing both GNRH pulsatility and $\mathrm{LH}$ secretion. Both hyperinsulinemia and 
relative $\mathrm{LH}$ excess may then promote a progression toward the PCOS phenotype. Other pathophysiological factors likely play a role as well. For example, a body of data suggest that some women have inherent (possibly genetic) defects of ovarian and adrenal steroidogenesis that result in a tendency to excessive androgen production - a process that may be exacerbated by obesity-related hyperinsulinemia (Franks 2008). Also, some girls with exaggerated adrenarche appear to be at risk for future functional ovarian hyperandrogenism and PCOS; these findings could similarly reflect inherent abnormalities of steroidogenesis (Rosenfield 2007). It is also possible that peripubertal hyperandrogenemia from any source may have untoward effects (e.g. on neuroendocrine function) that lead to PCOS.

\section{Additional considerations}

It is likely that other factors play a role in obesityassociated hyperandrogenemia in peripubertal girls. For example, obesity is often associated with inflammation and marked changes of cytokines and adipokines. Although a detailed discussion of the potential roles of cytokines and adipokines in obesityrelated hyperandrogenemia is beyond the scope of this review, we provide one illustrative example. Concentrations of the proinflammatory cytokine interleukin-6 (IL6) are elevated in obesity, and IL6 can stimulate adrenal steroidogenesis, including androgen synthesis (Mastorakos et al. 1993, Path et al. 1997, Papanicolaou et al. 1998). Additionally, polymorphisms in the IL6 gene promoter and IL6 receptor may be associated with hyperandrogenemia (Villuendas et al. 2002, Escobar-Morreale et al. 2003, 2005, Walch et al. 2004), and IL6 can augment androgen receptor transactivation (Yang et al. 2003). Indeed, a synergistic effect of IL6 and androgens on the androgen receptor has been hypothesized to play a role in PCOS (Ibanez et al. 2004).

As a final note, an association between peripubertal obesity and hyperandrogenemia could in part reflect an ability of hyperandrogenemia to promote obesity, particularly central obesity. Androgen receptors are found in adipocytes, especially from visceral adipose tissue, and testosterone upregulates its own receptor in adipose tissue (Dieudonne et al. 1998). Exogenous androgen administration can increase central adiposity in women (Lovejoy et al. 1996, Elbers et al. 1997), while androgen blockade has been reported to reduce central adiposity in PCOS (Gambineri et al. 2006). Similarly, prenatally androgenized monkeys demonstrate increased central obesity in adulthood (Eisner et al. 2003). It also remains possible that unknown factors may predispose to both obesity and hyperandrogenemia in girls.

\section{Effects of obesity on linear growth during puberty}

In contrast to the short stature observed in children with obesity related to cortisol excess, children with simple obesity typically have normal or tall stature for age and family (Reiter \& Rosenfeld 2003). Accelerated weight gain is often accompanied by a similar acceleration of height velocity, and children with excess weight tend to have slightly advanced bone ages during early puberty (Reiter \& Rosenfeld 2003, Shalitin \& Phillip 2003). These findings probably reflect growth plate maturation in response to increased IGF1 bioavailability (likely related to insulin resistance) and early estrogenization. Despite acceleration of bone age and linear growth during puberty, children with obesity generally attain expected adult height, probably a reflection of early estrogenrelated epiphyseal closure (Shalitin \& Phillip 2003).

Although childhood obesity is associated with accelerated linear growth, spontaneous and stimulated $\mathrm{GH}$ levels are decreased in obese children (Ballerini et al. 2004, Bouhours-Nouet et al. 2007). However, obesity is also associated with normal or increased basal IGF1 levels, increased IGF1 generation after GH administration, increased $\mathrm{GH}$-binding protein levels, and normal $\mathrm{GH}-\mathrm{GH}-$ binding protein complexes (Ballerini et al. 2004, Bouhours-Nouet et al. 2007). These findings may imply increased sensitivity of IGF1 production to circulating $\mathrm{GH}$, increased $\mathrm{GH}$ receptor numbers, and a normal serum $\mathrm{GH}$ reservoir in obese children. Additionally, insulin resistance may suppress IGFBP1 and 2 levels, leading to greater IGF1 bioavailability (Ballerini et al. 2004).

Interestingly, some children with hypothalamic obesity from craniopharyngioma or other hypothalamic disorders may demonstrate appropriate linear growth even without GH production. Similarly, some adults with late diagnosis of congenital panhypopituitarism (including $\mathrm{GH}$ deficiency) exhibit normal or tall adult stature. This 'growth without $\mathrm{GH}^{\prime}$ phenomenon may be partially due to increased insulin action on the IGF1 receptor (Geffner 1996). This phenomenon may partly account for near-normal linear growth, despite reduced $\mathrm{GH}$ production in obese children. Altered sex steroid concentrations and cytoadipokines could play a role as well.

\section{Conclusions}

Obesity during childhood may lead to early signs of puberty (thelarche) in girls and pubertal delay in boys. It remains unclear whether early thelarche in overweight girls is related to central activation of the GNRHgonadotropin axis, but there are currently no data clearly supporting this notion. Early breast development may in part reflect increased peripheral aromatization of adrenal androgens in an expanded adipose tissue 
compartment. Hyperinsulinemia may play a prominent role in this regard.

Girls with obesity are at risk for hyperandrogenemia due to increased total testosterone production and reduced SHBG. Insulin resistance likely contributes to this association by stimulating adrenal and/or theca cell androgen production. Although early data suggest that $\mathrm{LH}$ values are relatively low in obese peripubertal girls, $\mathrm{LH}$ appears to be an independent predictor of free testosterone in this group. Hyperandrogenemia in adolescence may portend adult PCOS, along with its potential metabolic and cardiovascular complications.

Obesity is associated with accelerated linear growth during puberty, possibly due to early estrogenization and the action of insulin on the IGF1 receptor, among other potential mechanisms.

Many unanswered questions remain. For example, more research is needed to clearly delineate the effects of excess adiposity on pubertal development in both boys and girls. It also remains unclear how obesity influences pubertal gonadotropin and sex hormone production (e.g. do gonadotropin-dependent or gonadotropin-independent mechanisms underlie early thelarche in obese girls?). The presence and implications of hyperandrogenemia during early puberty need to be clarified as well. These issues will need to be addressed more fully in order to develop better screening tools for obesityrelated reproductive complications, in addition to potential preventative treatments beyond achievement of normal weight.

\section{Declaration of interest}

The authors declare that there is no conflict of interest that could be perceived as prejudicing the impartiality of the research reported.

\section{Funding}

This work was partly supported by R01 HD058671 (C R McCartney) and the Eunice Kennedy Shriver NICHD/NIH through cooperative agreement U54 HD 28934 (C M Burt Solorzano, C R McCartney).

\section{References}

Ahmed ML, Ong KK \& Dunger DB 2009 Childhood obesity and the timing of puberty. Trends in Endocrinology and Metabolism 20 237-242.

Auchus RJ \& Rainey WE 2004 Adrenarche - physiology, biochemistry and human disease. Clinical Endocrinology 60 288-296.

Baillargeon JP, luorno MJ \& Nestler JE 2003 Insulin sensitizers for polycystic ovary syndrome. Clinical Obstetrics and Gynecology $\mathbf{4 6}$ 325-340.

Ballerini MG, Ropelato MG, Domene HM, Pennisi P, Heinrich J \& Jasper HG 2004 Differential impact of simple childhood obesity on the components of the growth hormone-insulin-like growth factor (IGF)-IGF binding proteins axis. Journal of Pediatric Endocrinology and Metabolism 17 749-757.
Biro FM, Khoury P \& Morrison JA 2006 Influence of obesity on timing of puberty. International Journal of Andrology 29 272-277.

Blank SK, McCartney CR, Chhabra S, Helm KD, Eagleson CA, Chang RJ \& Marshall JC 2009 Modulation of GnRH pulse generator sensitivity to progesterone inhibition in hyperandrogenic adolescent girls - implications for regulation of pubertal maturation. Journal of Clinical Endocrinology and Metabolism 94 2360-2366.

Bordini B, Littlejohn E \& Rosenfield RL 2009 Blunted sleep-related luteinizing hormone rise in healthy premenarcheal pubertal girls with elevated body mass index. Journal of Clinical Endocrinology and Metabolism 94 1168-1175.

Bouhours-Nouet N, Gatelais F, Boux de Casson F, Rouleau S \& Coutant R 2007 The insulin-like growth factor-I response to growth hormone is increased in prepubertal children with obesity and tall stature. Journal of Clinical Endocrinology and Metabolism 92 629-635.

Boukouvalas G, Antoniou K, Papalexi E \& Kitraki E 2008 Post weaning high fat feeding affects rats' behavior and hypothalamic-pituitary-adrenal axis at the onset of puberty in a sexually dimorphic manner. Neuroscience 153 373-382.

Brill DS \& Moenter SM 2009 Androgen receptor antagonism and an insulin sensitizer block the advancement of vaginal opening by high-fat diet in mice. Biology of Reproduction 81 1093-1098.

Brufani C, Tozzi A, Fintini D, Ciampalini P, Grossi A, Fiori R, Kiepe D, Manco M, Schiaffini R, Porzio O et al. 2009 Sexual dimorphism of body composition and insulin sensitivity across pubertal development in obese Caucasian subjects. European Journal of Endocrinology 160 769-775.

Burt Solorzano CM, McCartney CR, Blank SK, Knudsen KL \& Marshall JC 2010 Hyperandrogenaemia in adolescent girls: origins of abnormal gonadotropin-releasing hormone secretion. British Journal of Obstetrics and Gynaecology 117 143-149.

Cali AM \& Caprio S 2008 Obesity in children and adolescents. Journal of Clinical Endocrinology and Metabolism 93 S31-S36.

Casazza K, Goran MI \& Gower BA 2008 Associations among insulin, estrogen, and fat mass gain over the pubertal transition in African-American and European-American girls. Journal of Clinical Endocrinology and Metabolism 93 2610-2615.

Chakrabarty S, Miller BT, Collins TJ \& Nagamani M 2006 Ovarian dysfunction in peripubertal hyperinsulinemia. Journal of the Society for Gynecologic Investigation 13 122-129.

Coutant R, de Casson FB, Rouleau S, Douay O, Mathieu E, Gatelais F, Bouhours-Nouet N, Voinot C, Audran M \& Limal JM 2004 Divergent effect of endogenous and exogenous sex steroids on the insulin-like growth factor I response to growth hormone in short normal adolescents. Journal of Clinical Endocrinology and Metabolism 89 6185-6192.

Davison KK, Susman EJ \& Birch LL 2003 Percent body fat at age 5 predicts earlier pubertal development among girls at age 9. Pediatrics 111 815-821.

Den Hond E \& Schoeters G 2006 Endocrine disrupters and human puberty. International Journal of Andrology 29 264-271.

Dieudonne MN, Pecquery R, Boumediene A, Leneveu MC \& Giudicelli Y 1998 Androgen receptors in human preadipocytes and adipocytes: regional specificities and regulation by sex steroids. American Journal of Physiology 274 C1645-C1652.

DiVall SA \& Radovick S 2009 Endocrinology of female puberty. Current Opinion in Endocrinology, Diabetes and Obesity 16 1-4.

Dunger DB, Ahmed ML \& Ong KK 2005 Effects of obesity on growth and puberty. Best Practice and Research. Clinical Endocrinology and Metabolism 19 375-390.

Eagleson CA, Gingrich MB, Pastor CL, Arora TK, Burt CM, Evans WS \& Marshall JC 2000 Polycystic ovarian syndrome: evidence that flutamide restores sensitivity of the gonadotropin-releasing hormone pulse generator to inhibition by estradiol and progesterone. Journal of Clinical Endocrinology and Metabolism 85 4047-4052.

Eisner JR, Dumesic DA, Kemnitz JW, Colman RJ \& Abbott DH 2003 Increased adiposity in female rhesus monkeys exposed to androgen excess during early gestation. Obesity Research 11 279-286.

Elbers JM, Asscheman H, Seidell JC, Megens JA \& Gooren LJ 1997 Longterm testosterone administration increases visceral fat in female to male transsexuals. Journal of Clinical Endocrinology and Metabolism 82 2044-2047. 
Escobar-Morreale HF, Calvo RM, Villuendas G, Sancho J \& San Millan JL 2003 Association of polymorphisms in the interleukin 6 receptor complex with obesity and hyperandrogenism. Obesity Research 11 987-996.

Escobar-Morreale HF, Luque-Ramirez M \& San Millan JL 2005 The molecular-genetic basis of functional hyperandrogenism and the polycystic ovary syndrome. Endocrine Reviews 26 251-282.

Euling SY, Herman-Giddens ME, Lee PA, Selevan SG, Juul A, Sorensen TI, Dunkel L, Himes JH, Teilmann G \& Swan SH 2008 Examination of US puberty-timing data from 1940 to 1994 for secular trends: panel findings. Pediatrics 121 (Supplement 3) S172-S191.

Franks S 2002 Adult polycystic ovary syndrome begins in childhood. Best Practice and Research. Clinical Endocrinology and Metabolism 16 263-272.

Franks S 2008 Polycystic ovary syndrome in adolescents. International Journal of Obesity 32 1035-1041.

Freedman DS, Khan LK, Serdula MK, Dietz WH, Srinivasan SR \& Berenson GS 2002 Relation of age at menarche to race, time period, and anthropometric dimensions: the Bogalusa Heart Study. Pediatrics 110 e43.

Fu JF, Dong GP, Liang L, Jiang YJ, Chen LQ \& Dayan C 2006 Early activation of the inhibin B/FSH axis in obese Tanner stage G1PH1 boys. Clinical Endocrinology 65 327-332.

Gambineri A, Patton L, Vaccina A, Cacciari M, Morselli-Labate AM, Cavazza C, Pagotto U \& Pasquali R 2006 Treatment with flutamide, metformin, and their combination added to a hypocaloric diet in overweight-obese women with polycystic ovary syndrome: a randomized, 12-month, placebo-controlled study. Journal of Clinical Endocrinology and Metabolism 91 3970-3980.

Geffner ME 1996 The growth without growth hormone syndrome. Endocrinology and Metabolism Clinics of North America 25 649-663.

Golub MS, Collman GW, Foster PM, Kimmel CA, Rajpert-De Meyts E, Reiter EO, Sharpe RM, Skakkebaek NE \& Toppari J 2008 Public health implications of altered puberty timing. Pediatrics 121 (Supplement 3) S218-S230.

Grumbach MM 2002 The neuroendocrinology of human puberty revisited. Hormone Research 57 (Supplement 2) 2-14.

Hammoud AO, Gibson M, Peterson CM, Hamilton BD \& Carrell DT 2006 Obesity and male reproductive potential. Journal of Andrology 27 619-626.

Herman-Giddens ME, Slora EJ, Wasserman RC, Bourdony CJ, Bhapkar MV, Koch GG \& Hasemeier CM 1997 Secondary sexual characteristics and menses in young girls seen in office practice: a study from the Pediatric Research in Office Settings network. Pediatrics 99 505-512.

Hoffman RP 2009 Metabolic syndrome racial differences in adolescents. Current Diabetes Reviews 5 259-265.

Ibanez L, Dimartino-Nardi J, Potau N \& Saenger P 2000 Premature adrenarche - normal variant or forerunner of adult disease? Endocrine Reviews 21 671-696.

Ibanez L, Valls C, Cabre S \& De Zegher F 2004 Flutamide-metformin plus ethinylestradiol-drospirenone for lipolysis and antiatherogenesis in young women with ovarian hyperandrogenism: the key role of early, low-dose flutamide. Journal of Clinical Endocrinology and Metabolism 89 4716-4720.

Ibanez L, Jimenez R \& de Zegher F 2006a Early puberty-menarche after precocious pubarche: relation to prenatal growth. Pediatrics 117 117-121.

Ibanez L, Ong K, Valls C, Marcos MV, Dunger DB \& de Zegher F $2006 b$ Metformin treatment to prevent early puberty in girls with precocious pubarche. Journal of Clinical Endocrinology and Metabolism 91 2888-2891.

Ibanez L, Valls C, Ong K, Dunger DB \& de Zegher F 2006c Metformin therapy during puberty delays menarche, prolongs pubertal growth, and augments adult height: a randomized study in low-birth-weight girls with early-normal onset of puberty. Journal of Clinical Endocrinology and Metabolism 91 2068-2073.

Jasik CB \& Lustig RH 2008 Adolescent obesity and puberty: the "perfect storm". Annals of the New York Academy of Sciences 1135 265-279.

Kaplowitz P 1998 Delayed puberty in obese boys: comparison with constitutional delayed puberty and response to testosterone therapy. Journal of Pediatrics 133 745-749.
Kaplowitz P 2006 Pubertal development in girls: secular trends. Current Opinion in Obstetrics and Gynecology 18 487-491.

Kaplowitz PB 2008 Link between body fat and the timing of puberty. Pediatrics 121 (Supplement 3) S208-S217.

Kaplowitz PB, Slora EJ, Wasserman RC, Pedlow SE \& Herman-Giddens ME 2001 Earlier onset of puberty in girls: relation to increased body mass index and race. Pediatrics 108 347-353.

Knudsen KL, Blank SK, Burt Solorzano C, Patrie JT, Chang RJ, Caprio S, Marshall JC \& McCartney CR 2010 Hyperandrogenemia in obese peripubertal girls: correlates and potential etiological determinants. Obesity [in press]. DOI: 10.1038/oby.2010.58.

Lee JM 2006 Insulin resistance in children and adolescents. Reviews in Endocrine and Metabolic Disorders 7 141-147.

Lee PA \& Houk CP 2007 Puberty and its disorders. In Pediatric Endocrinology, 5th edn, pp 283. Ed. F Lifshitz. New York: Informa Healthcare USA, Inc.

Lee JM, Appugliese D, Kaciroti N, Corwyn RF, Bradley RH \& Lumeng JC 2007 Weight status in young girls and the onset of puberty. Pediatrics 119 e624-e630.

Lee JM, Kaciroti N, Appugliese D, Corwyn RF, Bradley RH \& Lumeng JC 2010 Body mass index and timing of pubertal initiation in boys. Archives of Pediatrics \& Adolescent Medicine 164 139-144.

Lovejoy JC, Bray GA, Bourgeois MO, Macchiavelli R, Rood JC, Greeson C \& Partington C 1996 Exogenous androgens influence body composition and regional body fat distribution in obese postmenopausal women - a clinical research center study. Journal of Clinical Endocrinology and Metabolism 81 2198-2203.

Mansfield MJ, Rudlin CR, Crigler JF Jr, Karol KA, Crawford JD, Boepple PA \& Crowley WF Jr 1988 Changes in growth and serum growth hormone and plasma somatomedin-C levels during suppression of gonadal sex steroid secretion in girls with central precocious puberty. Journal of Clinical Endocrinology and Metabolism 66 3-9.

Marshall WA \& Tanner JM 1969 Variations in pattern of pubertal changes in girls. Archives of Disease in Childhood 44 291-303.

Marshall WA \& Tanner JM 1970 Variations in the pattern of pubertal changes in boys. Archives of Disease in Childhood 45 13-23.

Martos-Moreno GA, Chowen JA \& Argente J 2010 Metabolic signals in human puberty: effects of over and undernutrition. Molecular and Cellular Endocrinology 324 70-81.

Mastorakos G, Chrousos GP \& Weber JS 1993 Recombinant interleukin-6 activates the hypothalamic-pituitary-adrenal axis in humans. Journal of Clinical Endocrinology and Metabolism 77 1690-1694.

Mauras N 2001 Growth hormone and sex steroids. Interactions in puberty. Endocrinology and Metabolism Clinics of North America 30 529-544.

McCartney CR, Prendergast KA, Chhabra S, Eagleson CA, Yoo R, Chang RJ, Foster CM \& Marshall JC 2006 The association of obesity and hyperandrogenemia during the pubertal transition in girls: obesity as a potential factor in the genesis of postpubertal hyperandrogenism. Journal of Clinical Endocrinology and Metabolism 91 1714-1722.

McCartney CR, Blank SK, Prendergast KA, Chhabra S, Eagleson CA, Helm KD, Yoo R, Chang RJ, Foster CM, Caprio S et al. 2007 Obesity and sex steroid changes across puberty: evidence for marked hyperandrogenemia in pre- and early pubertal obese girls. Journal of Clinical Endocrinology and Metabolism 92 430-436.

McCartney CR, Prendergast KA, Blank SK, Helm KD, Chhabra S \& Marshall JC 2009 Maturation of luteinizing hormone (gonadotropinreleasing hormone) secretion across puberty: evidence for altered regulation in obese peripubertal girls. Journal of Clinical Endocrinology and Metabolism 94 56-66.

McLachlan JA, Simpson E \& Martin M 2006 Endocrine disrupters and female reproductive health. Best Practice and Research. Clinical Endocrinology and Metabolism 20 63-75.

Moran A, Jacobs DR Jr, Steinberger J, Cohen P, Hong CP, Prineas R \& Sinaiko AR 2002 Association between the insulin resistance of puberty and the insulin-like growth factor-l/growth hormone axis. Journal of Clinical Endocrinology and Metabolism 87 4817-4820.

Ogden CL, Flegal KM, Carroll MD \& Johnson CL 2002 Prevalence and trends in overweight among US children and adolescents, 1999-2000. Journal of the American Medical Association 288 1728-1732.

Ogden CL, Carroll MD, Curtin LR, Lamb MM \& Flegal KM 2010 Prevalence of high body mass index in US children and adolescents, 2007-2008. Journal of the American Medical Association 303 242-249. 
Ojeda SR, Roth C, Mungenast A, Heger S, Mastronardi C, Parent AS, Lomniczi A \& Jung H 2006 Neuroendocrine mechanisms controlling female puberty: new approaches, new concepts. International Journal of Andrology 29 256-263 (discussion 286-290).

Ong KK, Ahmed ML \& Dunger DB 2006 Lessons from large population studies on timing and tempo of puberty (secular trends and relation to body size): the European trend. Molecular and Cellular Endocrinology 254-255 8-12.

Papanicolaou DA, Wilder RL, Manolagas SC \& Chrousos GP 1998 The pathophysiologic roles of interleukin-6 in human disease. Annals of Internal Medicine 128 127-137.

Partsch CJ \& Sippell WG 2001 Pathogenesis and epidemiology of precocious puberty. Effects of exogenous oestrogens. Human Reproduction Update 7 292-302.

Path G, Bornstein SR, Ehrhart-Bornstein M \& Scherbaum WA 1997 Interleukin-6 and the interleukin-6 receptor in the human adrenal gland: expression and effects on steroidogenesis. Journal of Clinical Endocrinology and Metabolism 82 2343-2349.

Pielecka J, Quaynor SD \& Moenter SM 2006 Androgens increase gonadotropinreleasing hormone neuron firing activity in females and interfere with progesterone negative feedback. Endocrinology 147 1474-1479.

Pilia S, Casini MR, Foschini ML, Minerba L, Musiu MC, Marras V, Civolani P \& Loche S 2009 The effect of puberty on insulin resistance in obese children. Journal of Endocrinological Investigation 32 401-405.

Plant TM 2008 Hypothalamic control of the pituitary-gonadal axis in higher primates: key advances over the last two decades. Journal of Neuroendocrinology 20 719-726.

Poretsky L, Cataldo NA, Rosenwaks Z \& Giudice LC 1999 The insulinrelated ovarian regulatory system in health and disease. Endocrine Reviews 20 535-582.

Reinehr T, de Sousa G, Roth CL \& Andler W 2005 Androgens before and after weight loss in obese children. Journal of Clinical Endocrinology and Metabolism 90 5588-5595.

Reiter EO \& Rosenfeld RG 2003 Normal and aberrant growth. In Williams Textbook of Endocrinology, 10th edn, pp 1003-1114. Eds PR Larsen, HM Kronenberg, S Melmed \& KS Polonsky. Philadelphia: Saunders.

Robinson JE, Forsdike RA \& Taylor JA 1999 In utero exposure of female lambs to testosterone reduces the sensitivity of the gonadotropinreleasing hormone neuronal network to inhibition by progesterone. Endocrinology 140 5797-5805.

Roemmich JN, Clark PA, Lusk M, Friel A, Weltman A, Epstein LH \& Rogol AD 2002 Pubertal alterations in growth and body composition. VI. Pubertal insulin resistance: relation to adiposity, body fat distribution and hormone release. International Journal of Obesity and Related Metabolic Disorders 26 701-709.

Rosenfield RL 2007 Clinical review: identifying children at risk for polycystic ovary syndrome. Journal of Clinical Endocrinology and Metabolism 92 787-796.

Rosenfield RL, Lipton RB \& Drum ML 2009 Thelarche, pubarche, and menarche attainment in children with normal and elevated body mass index. Pediatrics 123 84-88.
Saenger P \& Dimartino-Nardi J 2001 Premature adrenarche. Journal of Endocrinological Investigation 24 724-733.

Shalitin S \& Phillip M 2003 Role of obesity and leptin in the pubertal process and pubertal growth - a review. International Journal of Obesity and Related Metabolic Disorders 27 869-874.

Shayya R \& Chang RJ 2010 Reproductive endocrinology of adolescent polycystic ovary syndrome. British Journal of Obstetrics and Gynaecology 117 150-155.

Slyper AH 2006 The pubertal timing controversy in the USA, and a review of possible causative factors for the advance in timing of onset of puberty. Clinical Endocrinology 65 1-8.

Sun SS, Schubert CM, Chumlea WC, Roche AF, Kulin HE, Lee PA, Himes JH \& Ryan AS 2002 National estimates of the timing of sexual maturation and racial differences among US children. Pediatrics 110 911-919.

Tena-Sempere M 2008 Ghrelin as a pleotrophic modulator of gonadal function and reproduction. Nature Clinical Practice. Endocrinology \& Metabolism 4 666-674.

Terasawa E \& Fernandez DL 2001 Neurobiological mechanisms of the onset of puberty in primates. Endocrine Reviews 22 111-151.

Tfayli H \& Arslanian S 2008 Menstrual health and the metabolic syndrome in adolescents. Annals of the New York Academy of Sciences 1135 85-94.

Villuendas G, San Millan JL, Sancho J \& Escobar-Morreale HF 2002 The $-597 \mathrm{G} \rightarrow \mathrm{A}$ and $-174 \mathrm{G} \rightarrow \mathrm{C}$ polymorphisms in the promoter of the IL-6 gene are associated with hyperandrogenism. Journal of Clinical Endocrinology and Metabolism 87 1134-1141.

Walch K, Grimm C, Zeillinger R, Huber JC, Nagele F \& Hefler LA 2004 A common interleukin-6 gene promoter polymorphism influences the clinical characteristics of women with polycystic ovary syndrome. Fertility and Sterility 81 1638-1641.

Wang Y 2002 Is obesity associated with early sexual maturation? A comparison of the association in American boys versus girls. Pediatrics 110 903-910.

Wang Y \& Lobstein T 2006 Worldwide trends in childhood overweight and obesity. International Journal of Pediatric Obesity 1 11-25.

Witchel SF 2006 Puberty and polycystic ovary syndrome. Molecular and Cellular Endocrinology 254-255 146-153.

Yang L, Wang L, Lin HK, Kan PY, Xie S, Tsai MY, Wang PH, Chen YT \& Chang C 2003 Interleukin-6 differentially regulates androgen receptor transactivation via PI3K-Akt, STAT3, and MAPK, three distinct signal pathways in prostate cancer cells. Biochemical and Biophysical Research Communications 305 462-469.

Received 3 March 2010

First decision 16 April 2010

Revised manuscript received 1 June 2010

Accepted 16 June 2010 